\title{
NATURAL CONVECTION FROM A PLANE, VERTICAL SURFACE IN NON-ISOTHERMAL SURROUNDINGS
}

\author{
R. CHEESEWRIGHT $\dagger$
}

(Received 1 February 1967 and in revised form 27 June 1967)

\begin{abstract}
This paper presents a theoretical investigation of laminar natural convection from a plane, vertical surface in non-isothermal surroundings. Conditions are derived for the existence of similarity solutions. A method is proposed for generalizing the conditions pertaining to existing similarity solutions so as to include the effect of non-isothermal surroundings. Numerical solutions of the ordinary differential equations resulting from the similarity transformation are reported for the special case of an isothermal surface. These results suggest that some variations of surrounding temperature may lead to flow reversal in the boundary layer. Experimental evidence suggests that this may be an unstable condition.
\end{abstract}

NOMENCLATURE

$A, B, C, D$,

$C_{1}, C_{2}$, etc., constants;

$C_{p}$,

$f$

$g$

G,

$k$,

$L$,

$m, n$,

$\mathrm{Nu}$,

$P$,

Pr,

$Q^{\prime \prime}$,

$\mathrm{Re}$,

$T$,

$t$

$t^{*}$

$u$,

$v$

$x$ specific heat capacity;

dimensionless similarity stream

function $\left(=\Psi / \varphi_{2}\right)$;

specific gravitational force;

dimensionless temperature $(=$ $\left.g \beta L^{3}\left(\theta-\theta_{0}\right) / \nu^{2}\right)$

thermal conductivity;

characteristic length;

constant parameters;

Nusselt number $\left(=Q^{\prime \prime} L / k \Delta \theta\right)$;

pressure;

Prandtl number $\left(=\mu C_{p} / k\right)$;

heat-transfer rate per area;

free stream Reynolds number $\left(=U_{\infty} L / v\right)$;

absolute temperature;

time;

dimensionless time $\left(=v t / L^{2}\right)$;

velocity in the $x$ direction;

velocity in the $y$ direction;

distance along the plate; $\dagger$ Lecturer in Mechanical Engineering at Queen Mary College University of London. (Presently on leave in the Department of Nuclear Engineering, University of Michigan,
$X$

$y$,

$Y$,

Greek symbols

$\beta$,

$\varepsilon$,

$\eta$

$\theta$

$\mu$

$v$,

$\rho$,

$\varphi_{1}, \varphi_{2}$,

$\Phi$,

$\psi$

$\Psi$

$\Omega$,

dimensionless distance along the plate $(=x / L)$;

distance normal to the plate; dimensionless distance normal to the plate $(=y / L)$.

coefficient of cubical expansion; constant parameter; independent similarity variable $\left(=Y \varphi_{1}\right)$

temperature;

viscosity;

kinematic viscosity;

density;

unknown functions;

dimensionless similarity temperature function $\left[=\left(G-G_{\infty}\right) /\right.$ $\left.\left(G_{w}-G_{\infty}\right)\right]$;

stream function $(u=\partial \psi / \partial y, v=$ $-\partial \psi / \partial x)$

dimensionless stream function $(=\psi / v)$;

body force term in boundarylayer equation.

\section{Subscripts}

$w$, conditions on the surface of the heated plate; 
$\infty$,

0 ,

\section{Superscripts}

the prime is used to indicate differentiation with respect to the independent variable.

\section{INTRODUCTION}

Following the work of Yang [1], it has been suggested that all the "exact" similarity solutions for the above problem have been explored. However, during a recent experimental investigation (Cheesewright $[2,16]$ ), it became apparent that existing solutions, which are all concerned with isothermal surroundings, did not provide a satisfactory description of the experimental phenomena.

A study of the problem revealed a new class of solutions for non-isothermal surroundings. The derivation of these solutions and the numerical results arising from them are considered in this paper. The form of temperature variation in the surroundings considered is that in which the temperature far away from the heated plate is a function of $x$, the distance from the leading edge.

The procedure adopted by Yang [1] for the determination of the similarity transformation is followed closely, and after detailed examination of two cases of special interest, a way of generalizing the results of Yang [1] to include cases of non-isothermal surroundings is proposed.

It is believed that the results for the special case of an isothermal surface in non-isothermal surroundings have important applications in the experimental study of transition to turbulence in natural convection on a plane vertical surface. The results in general make possible the consideration of natural convection from an isolated surface in a cavity of limited extent, and may also facilitate the study of the boundarylayer regimes in natural convection in closed cavities. A qualitative study of the effects of a vertical temperature gradient outside the boundary layer in the closed cavity problem has been made by Schwind and Vliet [3].

\section{ANALYSIS}

With respect to the coordinate system, Fig. 1, the equations of momentum, continuity and energy which govern the flow and heat transfer in a laminar boundary layer in the presence of a body force are respectively

$$
\begin{gathered}
\frac{\partial u}{\partial t}+u \frac{\partial u}{\partial x}+v \frac{\partial u}{\partial y}=-\frac{1}{\rho} \frac{\mathrm{d} P}{\mathrm{~d} x}+\Omega+v \frac{\partial^{2} u}{\partial y^{2}} \\
\frac{\partial u}{\partial x}+\frac{\partial v}{\partial y}=0 \\
\frac{\partial \theta}{\partial t}+u \frac{\partial \theta}{\partial x}+v \frac{\partial \theta}{\partial y}=\frac{k}{\rho C_{p}} \frac{\partial^{2} \theta}{\partial y^{2}}
\end{gathered}
$$

with the appropriate boundary conditions.

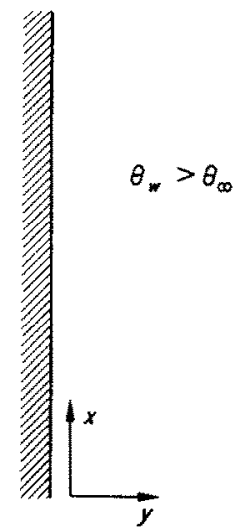

Fig. 1. Coordinate system.

If consideration is restricted to a region of plate (which may or may not include the leading edge), having a temperature everywhere greater than, or equal to that of its surroundings, we can write $\Omega=-g$. It should be noted that for cases in which $\theta_{w}-\theta_{\infty}$ decreases with distance up the plate, the above restrictions lead to the consideration of a region of limited extent rather 
than the semi-infinite region usually considered in boundary-layer problems. At no time, however, will consideration be given to effects due to a region having a trailing edge.

Outside the boundary layer

$$
\frac{\partial u_{\infty}}{\partial t}+u_{\infty} \frac{\partial u_{\infty}}{\partial x}+\frac{1}{\rho_{\infty}} \frac{\mathrm{d} P}{\mathrm{~d} x}+g=0
$$

(for pure natural convection $u_{\infty}=0$ ).

Eliminating $\mathrm{d} P / \mathrm{d} x$ between equations (1) and (4), we get

$$
\begin{aligned}
& \rho\left(\frac{\partial u}{\partial t}+u \frac{\partial u}{\partial x}+v \frac{\partial u}{\partial y}\right)=\rho_{\infty}\left(\frac{\partial u_{\infty}}{\partial t}+u_{\infty} \frac{\partial u_{\infty}}{\partial x}\right) \\
&-g\left(\rho-\rho_{\infty}\right)+\mu \frac{\partial^{2} u}{\partial y^{2}} .
\end{aligned}
$$

Following Ostrach [4], property variations are assumed to be important only in so far as they affect the body force term, and the density variation is represented by

$$
\rho=\rho_{0}\left[1-\beta\left(\theta-\theta_{0}\right)\right] .
$$

Where $\rho_{0}$ is the density at an arbitrary reference temperature, $\theta_{0}$, and $\beta=$ constant $\left(1 / T_{0}\right.$ for a perfect gas).

These considerations allow us to rewrite equation (5) as

$$
\begin{aligned}
\frac{\partial u}{\partial t}+u \frac{\partial u}{\partial x}+v \frac{\partial u}{\partial y} & =\frac{\partial u_{\infty}}{\partial t}+u_{\infty} \frac{\partial u_{\infty}}{\partial x} \\
& +g \beta\left(\theta-\theta_{\infty}\right)+v \frac{\partial^{2} u}{\partial y^{2}}
\end{aligned}
$$

provided $\left(\theta-\theta_{0}\right) \ll T_{0}$.

Equations $(2,3,6)$ govern the flow which wè wish to investigate, subject to the following boundary conditions

$$
\begin{array}{cc}
\text { at } y=0 & u=v=0 \text { and } \theta=\theta_{w}(x, t) \\
\text { at } y=\infty & u=u_{\infty}(x, t) \text { and } \theta=\theta_{\infty}(x, t) .
\end{array}
$$

It may be noted that equation (6) is identical with the corresponding equation for the case $\theta_{\infty}=$ constant. The above derivation has been given because it is not felt that this identity is obvious.
Introducing the stream function $\psi$, [which satisfies equation (2)], equations (6) and (3) become

$$
\begin{gathered}
\frac{\partial^{2} \psi}{\partial y \partial t}+\frac{\partial \psi}{\partial y} \frac{\partial^{2} \psi}{\partial x \partial y}-\frac{\partial \psi}{\partial x} \frac{\partial^{2} \psi}{\partial y^{2}}=\frac{\partial u_{\infty}}{\partial t}+u_{\infty} \frac{\partial u_{\infty}}{\partial x} \\
+g \beta\left(\theta-\theta_{\infty}\right)+v \frac{\partial^{3} \psi}{\partial y^{3}} \\
\frac{\partial \theta}{\partial t}+\frac{\partial \psi}{\partial y} \frac{\partial \theta}{\partial x}-\frac{\partial \psi}{\partial x} \frac{\partial \theta}{\partial y}=\frac{k}{\rho C_{p}} \frac{\partial^{2} \theta}{\partial y^{2}}
\end{gathered}
$$

It is convenient to make these equations dimensionless by writing $X=x / L, Y=y / L$, $\Psi=\psi / v, \quad R e=u_{\infty} L / v, \quad G=\beta g L^{3}\left(\theta-\theta_{0}\right) / v^{2}$, $G_{\infty}=\beta g L^{3}\left(\theta_{\infty}-\theta_{0}\right) / v^{2}$ and $t^{*}=v t / L^{2}$ where $L$ is a characteristic length.

Equations (7) and (8) now become

$$
\begin{gathered}
\frac{\partial^{2} \Psi}{\partial y \partial t^{*}}+\frac{\partial \Psi}{\partial y} \frac{\partial^{2} \Psi}{\partial x \partial y}-\frac{\partial \Psi}{\partial x} \frac{\partial^{2} \Psi}{\partial y^{2}}=\frac{\partial R e}{\partial t^{*}}+R e \frac{\partial R e}{\partial x} \\
+G-G_{\infty}+\frac{\partial^{3} \Psi}{\partial Y^{3}} \\
\frac{\partial G}{\partial t^{*}}+\frac{\partial \Psi}{\partial Y} \frac{\partial G}{\partial X}-\frac{\partial \Psi}{\partial X} \frac{\partial G}{\partial Y}=\frac{1}{\operatorname{Pr} \frac{\partial^{2} G}{\partial Y^{2}}}
\end{gathered}
$$

where $\operatorname{Pr}=\mu C_{p} / k$.

In order to determine the necessary conditions for the existence of similarity solutions, we follow Yang [1] and introduce the new variables

$$
\begin{gathered}
\eta=Y \varphi_{1}\left(X, t^{*}\right) \\
f(\eta)=\Psi / \varphi_{2}\left(X, t^{*}\right) \\
\Phi(\eta)=\left(G-G_{\infty}\right) /\left(G_{w}-G_{\infty}\right)
\end{gathered}
$$

where $G_{w}=\beta g L^{3}\left(\theta_{w}-\theta_{\infty}\right) / v^{2}$.

The required conditions are those which enable the introduction of the new variables to transform equations (9) and (10) into ordinary differential equations together with appropriate boundary conditions.

In terms of the new variables the boundary conditions become

$$
\begin{gathered}
\Phi=1 \quad \text { at } \eta=0, \quad \Phi=0 \text { at } \eta=\infty \\
f=\mathrm{d} f / \mathrm{d} \eta=0 \quad \text { at } \eta=0, \\
\text { d } f / \mathrm{d} \eta=\operatorname{Re} / \varphi_{1} \varphi_{2} \text { at } \eta=\infty
\end{gathered}
$$


Since the new boundary conditions must be independent of $X$ and $t^{*}$ we must have

$$
\frac{R e}{\varphi_{1} \varphi_{2}}=\text { constant }=C_{1} .
$$

The conditions for equations (9) and (10) to transform into ordinary differential equations may be seen, by comparison with the problem treated in Yang [1], to be given by

$$
\begin{gathered}
\frac{\left(G_{w}-G_{\infty}\right)}{\varphi_{1}^{3} \varphi_{2}}=C_{2} \\
\frac{\partial \varphi_{1}}{\partial t^{*}} \frac{1}{\varphi_{1}^{3}}=C_{3} \\
\frac{\partial \varphi_{2}}{\partial t^{*}} \frac{1}{\varphi_{1}^{2} \varphi_{2}}=C_{4} \\
\frac{\partial \varphi_{1}}{\partial X} \frac{\varphi_{2}}{\varphi_{1}^{2}}=C_{5} \\
\frac{\partial \varphi_{2}}{\partial X} \frac{1}{\varphi_{1}}=C_{6} \\
\frac{\partial\left(G_{w}-G_{\infty}\right)}{\partial t^{*}} \frac{1}{\left(G_{w}-G_{\infty}\right) \varphi_{1}^{2}}=C_{7} \\
\frac{\partial\left(G_{w}-G_{\infty}\right)}{\partial X} \frac{\varphi_{2}}{\left(G_{w}-G_{\infty}\right) \varphi_{1}}=C_{8} \\
\frac{\partial G_{\infty}}{\partial t^{*}} \frac{1}{\left(G_{w}-G_{\infty}\right) \varphi_{1}^{2}}=C_{9} \\
\frac{\partial G_{\infty}}{\partial X} \frac{\varphi_{2}}{\left(G_{w}-G_{\infty}\right) \varphi_{1}}=C_{10} \\
\frac{\partial R e}{\partial X} \frac{R e}{\varphi_{1}^{3} \varphi_{2}}=C_{11} \\
\frac{\partial R e}{\partial t^{*}} \frac{1}{\varphi_{1}^{3} \varphi_{2}}=C_{12}
\end{gathered}
$$

where the $C$ 's are all constants

Since, in general, we have twelve equations imposing conditions on five quantities, there are seven relations between the constants. These are :

$$
\begin{aligned}
& C_{3} C_{5}=-C_{4} C_{5} \\
& C_{3} C_{6}=2 C_{4} C_{5}+C_{4} C_{6}
\end{aligned}
$$

$$
\begin{aligned}
C_{7} & =3 C_{3}+C_{4} \\
C_{8} & =3 C_{5}+C_{6} \\
4 C_{3} C_{10} & =5 C_{9} C_{5}+C_{9} C_{6} \\
C_{11} & =C_{1}^{2}\left(C_{5}+C_{6}\right) \\
C_{12} & =C_{1}\left(C_{3}+C_{4}\right) .
\end{aligned}
$$

At this point it is desirable to consider the relationship between the present work and that contained in Yang [1] and other related publications.

The work of Yang [1] and, indeed, all other theoretical treatments of laminar natural convection from a plane surface in an infinite medium, known to the author, are concerned with convection from a surface in isothermal surroundings. The present investigation deals with convection from a surface in surroundings in which the temperature is a function of the distance along the plate and of time. Now it might be supposed that, as for forced convection (e.g. Hansen [5]), only the difference in temperature between the surface and the surroundings is important. However, this is not the case in problems of natural convection, because of the appearance of $\theta_{\infty}$ in the body force term in the momentum equation.

It should be noted that the present work includes all cases treated previously, including those of Yang [1]. This is demonstrated by putting $G_{\infty}=$ const. and $R e=0$ in equations (11-22), and writing $G_{w}^{*}=G_{w}-G_{\infty}$, when these equations become identical to equations (16-22) in Yang [1].

Two cases are of particular interest, viz. steady natural convection, (a) from an isothermal surface in non-isothermal surroundings; (b) from a non-isothermal surface maintained at a constant temperature differential with its surroundings.

\section{PARTICULAR CASES}

(i) Steady natural convection from an isothermal surface in non-isothermal surroundings

In this case $R e=0, \theta_{w}=$ const., $\theta_{\infty}=\theta_{\infty}(x)$ 
and hence $C_{1}=C_{3}=C_{4}=C_{7}=C_{9}=C_{11}=$ $C_{12}=0$ and $C_{8}=-C_{10}$. Equations (12), (15), (16) and (18) determine the conditions which are imposed on $\varphi_{1}, \varphi_{2}$ and $G_{\infty}$. A study of the general solutions to equations (15) and (16) shows that two cases must now be considered.

Case (a): $C_{6} / C_{5} \neq 1$. Here

$$
\begin{gathered}
\varphi_{1}=\left[C_{14}+\left(C_{5} / C_{13}\right)(\varepsilon-1) X\right]^{1 /(\varepsilon-1)} \\
\varphi_{2}=C_{13}\left[C_{14}+\left(C_{5} / C_{13}\right)(\varepsilon-1) X\right]^{e /(\varepsilon-1)}
\end{gathered}
$$

and

$$
\begin{aligned}
G_{w}-G_{\infty} & =C_{2} C_{13}\left[C_{14}\right. \\
& \left.+\left(C_{5} / C_{13}\right)(\varepsilon-1) X\right]^{(\varepsilon+3) /(\varepsilon-1)}
\end{aligned}
$$

where $\varepsilon=C_{6} / C_{5}$ and $C_{13}$ and $C_{14}$ are constants of integration.

Since $G_{w}-G_{\infty}$ is the quantity which is specified in any particular case, and since there can only be three independent constants in this problem, we are at liberty to specify two of the constants in equation (25) provided we retain the most general form. It is most convenient to write $C_{2}=1$ and $C_{5}(\varepsilon-1)=4$.

If we also write $n=(\varepsilon+3) /(\varepsilon-1)$ then equations (23-25) become

$$
\begin{gathered}
\varphi_{1}=\left[C_{14}+\left(4 / C_{13}\right) X\right]^{(n-1) / 4} \\
\varphi_{2}=C_{13}\left[C_{14}+\left(4 / C_{13}\right) X\right]^{(n+3) / 4} \\
G_{w}-G_{\infty}=C_{13}\left[C_{14}+\left(4 / C_{13}\right) X\right]^{n} .
\end{gathered}
$$

It may be easily demonstrated that the above specification of $C_{5}$ may be rewritten as $C_{5}=n$ -1 and that this implies that $C_{6}=n+3$ and $C_{8}=4 n$ and has the additional advantage that it enables the special case of $C_{5}=0$ to be retained in the general solution.

Under these conditions, equations (9) and (10) reduce to

$$
\begin{aligned}
& f^{\prime \prime \prime}+(n+3) f f^{\prime \prime}-2(n+1)\left(f^{\prime}\right)^{2}+\Phi=0 \\
& \Phi^{\prime \prime}+\operatorname{Pr}(n+3) f \Phi^{\prime}+4 n \operatorname{Pr} f^{\prime}(1-\Phi)=0
\end{aligned}
$$

where the prime indicates differentiation with respect to $\eta$. These equations, together with the appropriate boundary conditions, may be solved numerically.

Of particular interest are the heat-transfer rate from the surface and the component of velocity parallel to the surface.

$$
\begin{aligned}
& \begin{array}{c}
\dot{Q}^{\prime \prime}=-k\left(\frac{\partial \theta}{\partial y}\right)_{w}=\frac{k v^{2}}{g \beta L^{4}}\left[C_{14}\right. \\
\left.+\left(4 / C_{13}\right) X\right]^{(5 n-1) / 4} \Phi_{w}^{\prime}
\end{array} \\
& \begin{array}{r}
u=\frac{\partial \psi}{\partial y}=\varphi_{1} \varphi_{2} f^{\prime} \\
=C_{13}\left[C_{14}+\left(4 / C_{13}\right) X\right]^{(n+1) / 2} f^{\prime} .
\end{array}
\end{aligned}
$$

Expressing the heat-transfer rate in dimensionless form in terms of the Nusselt number, we obtain

$$
\begin{aligned}
N u=\frac{\dot{Q}^{\prime \prime} x}{k\left(\theta_{w}-\theta_{\infty}\right)}=\left[\frac{g \beta\left(\theta_{w}-\theta_{\infty}\right) L^{3}}{v^{2} C_{13}}\right]^{\ddagger} \frac{x}{L} \\
\times \frac{\Phi_{w}^{\prime}}{\left[C_{14}+\left(4 / C_{13}\right) X\right]^{4}}
\end{aligned}
$$

If $C_{14}=0$ this reduces to

$$
N u=(G r)^{\frac{1}{2}} \Phi_{w}^{\prime} /(2)^{\frac{1}{2}}
$$

where $G r=g \beta\left(\theta_{w}-\theta_{\infty}\right) x^{3} / v^{2}$.

The condition $C_{14}=0$ corresponds to the boundary-layer having zero thickness at $x=0$ and it is noted that, except for the special case of $G_{w}-G_{\infty}=$ constant $(n=0)$, zero boundarylayer thickness must always coincide with $G_{w}-$ $G_{\infty}=0$ for similarity solutions to exist.

Case (b): $C_{6} / C_{5}=1$. Here $\varphi_{2}=C_{15} \varphi_{1}$, $\varphi_{1}=C_{16} \exp \left(C_{5} X / C_{15}\right)$ and $G_{w}-G_{\infty}=$ $C_{2} C_{15} C_{16}^{4} \exp \left(4 C_{5} X / C_{15}\right)$ where $C_{15}$ and $C_{16}$ are constants of integration. By the same argument as in case (a) we can set $C_{2}=1$ and $C_{5}=1$ which implies that $C_{6}=1$ and $C_{8}=4$. If we also write $m=4 / C_{15}$ then

$$
\begin{gathered}
\varphi_{1}=C_{16} \exp (m X / 4) \\
\varphi_{2}=\left(4 C_{16} / m\right) \exp (m X / 4) \\
G_{w}-G_{\infty}=\left(4 C_{16}^{4} / m\right) \exp (m X)
\end{gathered}
$$


and equations (9) and (10) become

$$
\begin{gathered}
f^{\prime \prime \prime}+f f^{\prime \prime}-2\left(f^{\prime}\right)^{2}+\Phi=0 \\
\Phi^{\prime \prime}+\operatorname{Pr} f \Phi^{\prime}+4 \operatorname{Pr} f^{\prime}(1-\Phi)=0
\end{gathered}
$$

The corresponding forms for $Q^{\prime \prime}$ and $u$ are

$\dot{Q}^{\prime \prime}=-k\left(\frac{\partial \theta}{\partial y}\right)_{w}=\frac{-k v^{2}}{g \beta L^{4}}\left[4\left(C_{15}\right)^{5} / m\right]$ $\exp (5 m X / 4) \Phi_{w}^{\prime}$

$u=\frac{\partial \psi}{\partial y}=\varphi_{1} \varphi_{2} f^{\prime}=\left[4\left(C_{15}\right)^{2} / m\right] \exp (m X / 2) f^{\prime}$.

It is thus seen that similarity solutions for steady natural convection from an isothermal surface exist when the temperature of the surroundings varies either as a power of a linear function of $x$ as in the first case or as an exponential function of $x$ as above. The resulting equations are, in each case, similar but not identical to those for the corresponding cases of variable surface temperature and isothermal surroundings (Yang [1]).

Numerical solutions to equations (29) and (30) have been obtained for a range of values of $n$, i.e. different distributions of $\theta_{\infty}$.

(ii) Steady natural convection from a nonisothermal surface maintained at a constant temperature differential with its surroundings

Here $R e=0$ and $\theta_{w}(x)-\theta_{\infty}(x)=$ constant, so that $C_{1}=C_{3}=C_{4}=C_{7}=C_{8}=C_{9}=C_{11}$ $=C_{12}=0$ and equations (12), (15), (16) and (20) provide the conditions which must be satisfied if similarity solutions are to exist.

The general solution to equations (15) and (16) is given by equations (23) and (24) as in the previous case, provided $\varepsilon \neq 1$. (It may be easily demonstrated that the case $\varepsilon=1$ need not be considered as it does not lead to a solution for this particular problem.) Substituting equations (23) and (24) into equation (12) and requiring $G_{w}-G_{\infty}$ to be constant gives $\varepsilon=-3$ and $C_{2} C_{13}=G_{w}-G_{\infty}$.

Examination of this result shows that except for the constant of integration $C_{14}$, the functions $\varphi_{1}$ and $\varphi_{2}$ are identical with the corresponding functions occurring in the analysis of steady natural convection from an isothermal surface in isothermal surroundings.

We still have to satisfy equation (20) which may be rewritten as

$$
\frac{\mathrm{d} G_{\infty}}{\mathrm{d} X}=\frac{C_{10}\left(G_{w}-G_{\infty}\right)}{C_{13}\left[C_{14}-\left(4 / C_{13}\right) X\right]}
$$

Two cases must now be considered:

Case (a): $C_{5} \neq 0$. In this case we get,

$$
\begin{array}{r}
G_{\infty}= \\
-\frac{C_{10}\left(G_{w}-G_{\infty}\right) \ln \left[C_{14}\left(G_{w}-G_{\infty}\right)-4 C_{2} C_{5} X\right]}{4 C_{5}}+C_{15}
\end{array}
$$

where $C_{15}$ is a constant of integration.

In order that this may be applied to physically meaningful problems, $G_{\infty}$ must remain finite in the region of interest. This imposes the following mathematical restrictions

(i) $C_{14} \neq 0$

(ii) $C_{14}\left(G_{w}-G_{\infty}\right)>4 C_{2} C_{5} X$ for any $X$.

A study of the corresponding forms of $\varphi_{1}$ shows that the restrictions have the common interpretation that the existence of a constant temperature differential between a surface and its surroundings, is incompatible with the existence of a point of zero boundary-layer thickness, except for the special case of an isothermal surface in isothermal surroundings $\left(C_{10}=0\right)$.

When $C_{14} \neq 0$, the boundary-layer has a nonzero thickness at $X=0$ and the magnitudes of the temperature and velocity profiles are specified by the value of $C_{14}$.

For this case, equations (9) and (10) reduce to the ordinary differential equations

$$
\begin{aligned}
& f^{\prime \prime \prime}+3 f f^{\prime \prime}-2\left(f^{\prime}\right)^{2}+\Phi=0 \\
& \Phi^{\prime \prime}+3 \operatorname{Pr} f \Phi^{\prime}-C_{10} f^{\prime}=0 .
\end{aligned}
$$

Because the appearance of $C_{10}$ in equation (38) places a severe restriction on the generality 
of any solution and because of the limitations imposed on $C_{14}$, no numerical solutions of these equations have been attempted.

Case (b): $C_{5}=0$. Despite the difficulty in interpreting equations (23) and (24) for this case, it can be shown that if $C_{5}=0$ is inserted into equation (36), the correct form of expression for $\mathrm{d} G_{\infty} / \mathrm{d} X$ is obtained.

Thus

$$
G_{\infty}=\frac{C_{10}\left(G_{w}-G_{\infty}\right) X}{C_{13} C_{14}}+C_{15}
$$

where $C_{15}$ is a constant of integration.

This may be rewritten as

$$
G_{\infty}=\frac{C_{2} C_{10} X}{C_{14}}+C_{15}
$$

and as before, we are able to assign values to two of the constants. It is convenient to set $C_{2}$ $=C_{10}=1$. Under these conditions equations (9) and (10) reduce to

$$
f^{\prime \prime \prime}+\Phi=0
$$

and

$$
\Phi^{\prime \prime}-\operatorname{Pr} f^{\prime}=0 .
$$

Solutions to equations (39) and (40), which apply to a very special case of a boundary-layer having constant thickness, have not been obtained because that problem was not of direct interest in the general context of this work.

\section{(iii) Other cases of convection to non-isothermal surroundings}

A careful study of equations (11-21) shows that the conditions imposed by these equations are closely related to those which must be satisfied in problems with isothermal surroundings. Equations (11-18) impose the same conditions on $\left(G_{w}-G_{\infty}\right)$ as are usually imposed on $G_{w}$. Equations (19) and (20) then impose conditions on $G_{\infty}$ as well.

As an example, let us consider the case of steady natural convection from a non-isothermal surface to non-isothermal surroundings, excluding the case where $G_{w}-G_{\infty}$ is constant.

Similarity solutions are possible for $\left(G_{w}-G_{\infty}\right)$ $=(A+B X)^{n}$ and for $G_{w}-G_{\infty}=A \mathrm{e}^{m X}$ provided $G_{\infty}$ also satisfies equation (20) which requires that $G_{\infty}=C(A+B X)^{n}$ (for $n \neq 0$ ) in one case and $G_{\infty}=D \mathrm{e}^{m X}$ in the other case (The constants $A, B, C$ and $D$ are used here instead of the more complicated forms involving $C_{5}$ etc., in order to simplify the discussion.) The similarity in the form of $\left(G_{w}-G_{\infty}\right)$ $(X)$ and $G_{\infty}(X)$ results from the similarity of equations (17) and (19), and (18) and (20). This gives a means of generalizing existing results to include cases of non-isothermal surroundings. Restrictions previously derived concerning allowable variations in surface temperature may be used to describe allowable variations in temperature difference, surface to surroundings, provided that the same conditions are imposed on the variations of surrounding temperature alone. This generalization may be applied to all known similarity solutions for natural convection (see for example Yang [1], Pau-Chang $\mathrm{Lu}$ [6], Sparrow and Gregg [7], Eichhorn [8], etc.) and also to similarity solutions for combined forced and free convection (see Sparrow, Eichhorn and Gregg [9] and Brindley [10]).

It should be noted that the resulting ordinary differential equations in all these cases will not be the same as those for the corresponding cases of isothermal surroundings, but will, in each case, contain an additional term in the "energy" equation. Numerical solutions have not been obtained for any of the new equations, because practical applications have not yet arisen which would justify such work.

\section{RESULTS AND DISCUSSION}

Numerical solutions of equations (29) and (30) have been obtained on the University of London Atlas computer, for $-0.30 \leqslant n \leqslant 0.6$ and $\operatorname{Pr}=0.708$ (air). Details of the numerical methods used in these solutions and of the asymptotic properties of the equations are given in Appendix 1. 
Figures 2-4 show the influence of $n$ on the local heat-transfer rate, the temperature profiles and the velocity profiles respectively. Because of the difficulty of showing fine detail on the graphs, the full solutions are tabulated for the cases of $n=-0.15$ and $n=-0 \cdot 3$, in Tables 1 and 2.

It should be noted that $n<0$ corresponds to $\theta_{\infty}$ increasing with increasing $X$ while $n>0$ corresponds to $\theta_{\infty}$ decreasing with increasing $X$. The former of these is the more likely to occur in practical situations; in fact, the condition $n=0 \quad\left(\theta_{\infty}=\right.$ const. $)$ is very rarely achieved, although in many cases departures from it are small enough to be ignored. Cases of $n>0$ may not occur in practical situations because this would in general represent an unstable situation.

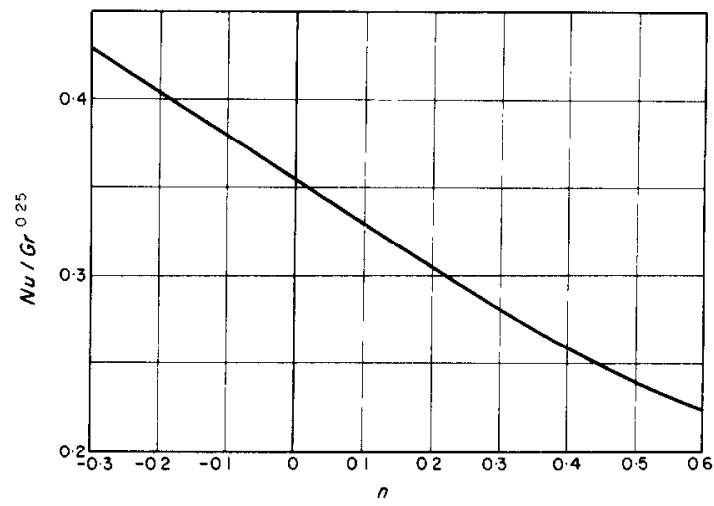

FIG. 2. The variation of the local heat-transfer rate with the temperature gradient outside the boundary layer. $\left(\theta_{\infty}=B x^{n}-\theta_{w}, \quad \theta_{w}=\right.$ const., $\left.\operatorname{Pr}=0.708\right)$

Figure 2 shows that for $n<0$, the local heat-transfer rate is increased as compared with $n \doteq 0$ while for $n>0$ it is reduced. This is in keeping with the physical picture of the phenomenon. For negative $n$ one would expect that at a particular section $X$, the temperatures at all points in the boundary layer would be less than would have existed if $n$ had been zero and $\theta_{w}-\theta_{\infty}$ had been everywhere equal to its local value. This picture is confirmed by the temperature and velocity profiles in Figs. 3 and 4.

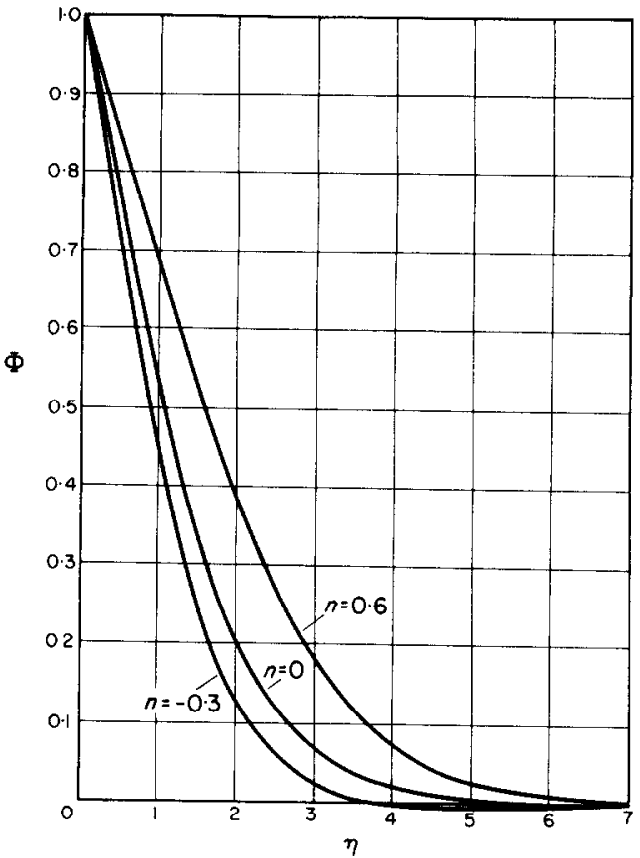

Fig. 3. The variation of the dimensionless temperature profiles with the temperature gradient outside the boundary layer.

$\left(\theta_{\infty}=B x^{n}-\theta_{w}, \quad \theta_{w}=\right.$ const., $\left.\quad \operatorname{Pr}=0.708\right)$

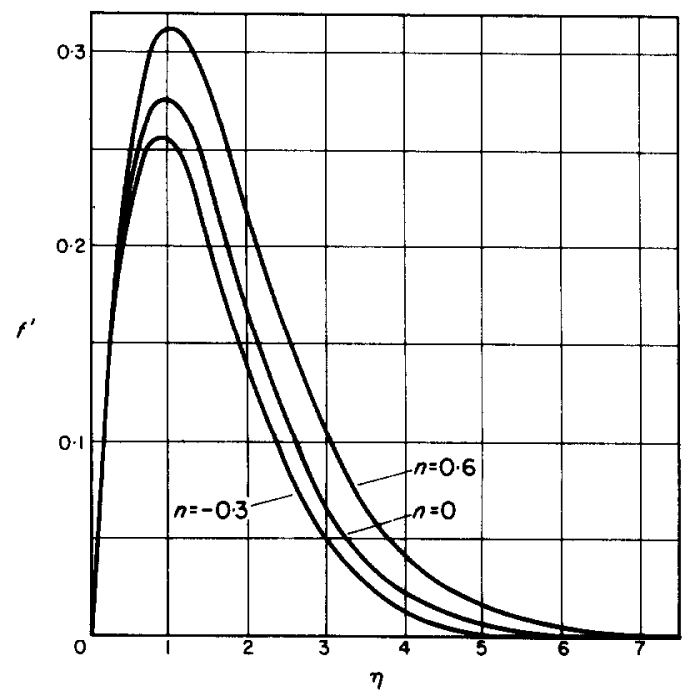

FIG. 4. The variation of the dimensionless velocity profiles with the temperature gradient outside the boundary layer. $\left(\theta_{\infty}=B x^{n}-\theta_{w}, \quad \theta_{w}=\right.$ const., $\left.\quad \operatorname{Pr}=0.708\right)$ 
Table 1. Theoretical solution $n=-0.15, \operatorname{Pr}=0.708$

\begin{tabular}{|c|c|c|c|c|c|}
\hline$\eta$ & $f$ & $f^{\prime}$ & $f^{\prime \prime}$ & $\Phi$ & $\Phi^{\prime}$ \\
\hline 0.00 & 0.00000 & 0.00000 & 0.65949 & $1 \cdot 00000$ & -0.55423 \\
\hline $0 \cdot 50$ & 0.06312 & 0.21703 & 0.23471 & 0.72515 & -0.53705 \\
\hline 1.00 & $0 \cdot 18846$ & 0.26296 & -0.02227 & $0 \cdot 47457$ & -0.45359 \\
\hline 1.50 & 0.31151 & $0 \cdot 22080$ & $-0 \cdot 12471$ & $0 \cdot 27956$ & -0.32318 \\
\hline $2 \cdot 00$ & 0.40539 & $0 \cdot 15430$ & -0.13975 & $0 \cdot 15026$ & -0.19855 \\
\hline $2 \cdot 50$ & 0.46734 & 0.09612 & -0.09939 & 0.07500 & -0.10901 \\
\hline $3 \cdot 00$ & 0.50448 & $0-05537$ & -006454 & 0.03525 & -0.05515 \\
\hline $3 \cdot 50$ & 0.52530 & 0.03012 & -0.03810 & $0 \cdot 01570$ & -0.02623 \\
\hline $4 \cdot 00$ & 0.53640 & 0.01568 & -0.02109 & 0.00662 & -0.01184 \\
\hline $4 \cdot 50$ & 0.54208 & 0.00786 & -0.01113 & 0.00261 & -0.00508 \\
\hline $5 \cdot 00$ & 0.54488 & $0 \cdot 00381$ & -0.00564 & $0 \cdot 00093$ & -0.00205 \\
\hline $5 \cdot 50$ & 0.54622 & 0.00178 & -0.00277 & $0 \cdot 00027$ & -0.00076 \\
\hline $6 \cdot 00$ & 0.54683 & 0.00081 & -0.00131 & 0.00004 & -0.00024 \\
\hline $6 \cdot 50$ & 0.54711 & 0.00035 & -0.00060 & $-0 \cdot 00002$ & -0.00005 \\
\hline 7.00 & 0.54723 & 0.00014 & -0.00026 & -0.00003 & $0 \cdot 00001$ \\
\hline $7 \cdot 50$ & 0.54727 & 0.00006 & -0.00011 & -0.00002 & 0.00002 \\
\hline 8.00 & 0.54729 & 0.00002 & -0.00004 & -0.00002 & 0.00002 \\
\hline $8 \cdot 50$ & 0.54730 & 0.00001 & -0.00002 & -0.00001 & 0.00001 \\
\hline 9.00 & 0.54730 & 0.00000 & -0.00000 & $-0 \cdot 00001$ & $0 \cdot 00001$ \\
\hline 9.50 & 0.54730 & -0.00000 & -0.00000 & $0 \cdot 00000$ & 0.00000 \\
\hline $10 \cdot 00$ & 0.54730 & -0.00000 & 0.00000 & $0 \cdot 00000$ & 0.00000 \\
\hline $10 \cdot 50$ & 0.54730 & -0.00000 & 0.00000 & $0 \cdot 00000$ & $0 \cdot 00000$ \\
\hline 11.00 & 0.54729 & -0.00000 & 0.00000 & 0.00000 & 0.00000 \\
\hline 11.50 & 0.54729 & -0.00000 & 0.00000 & 0.00000 & 0.00000 \\
\hline $12 \cdot 00$ & 0.54729 & -0.00000 & 0.00000 & 0.00000 & 0.00000 \\
\hline $12 \cdot 50$ & 0.54729 & 0.00000 & 0.00000 & $0 \cdot 00000$ & 0.00000 \\
\hline 13.00 & 0.54729 & 0.00000 & $0 \cdot 00000$ & 0.00000 & 0.00000 \\
\hline $13 \cdot 50$ & 0.54729 & $0 \cdot 00000$ & 0.00000 & $0 \cdot 00000$ & 0.00000 \\
\hline $14 \cdot 00$ & $0-54729$ & $0 \cdot 00000$ & 0.00000 & 0.00000 & 0.00000 \\
\hline $14 \cdot 50$ & 0.54730 & 0.00000 & 0.00000 & 0.00000 & $0 \cdot 00000$ \\
\hline $15 \cdot 00$ & 0.54730 & 0.00000 & 0.00000 & 0.00000 & 0.00000 \\
\hline $15 \cdot 50$ & 0.54730 & $0 \cdot 00000$ & 0.00000 & 0.00000 & 0.00000 \\
\hline $16 \cdot 00$ & 0.54730 & 0.00000 & $0 \cdot 00000$ & 0.00000 & 0.00000 \\
\hline $16 \cdot 50$ & 0.54730 & 0.00000 & -0.00000 & 0.00000 & 0.00000 \\
\hline $17 \cdot 00$ & 0.54730 & $0 \cdot 00000$ & -0.00000 & 0.00000 & 0.00000 \\
\hline $17 \cdot 50$ & 0.54730 & 0.00000 & -0.00000 & $0 \cdot 00000$ & 0.00000 \\
\hline $18 \cdot 00$ & 0.54730 & 0.00000 & -0.00000 & $0 \cdot 00000$ & 0.00000 \\
\hline $18 \cdot 50$ & 0.54730 & 0.00000 & -0.00000 & 0.00000 & 0.00000 \\
\hline $19 \cdot 00$ & 0.54730 & 0.00000 & -0.00000 & 0.00000 & 0.00000 \\
\hline $19 \cdot 50$ & 0.54730 & -0.00000 & -0.00000 & 0.00000 & 0.00000 \\
\hline $20 \cdot 00$ & 0.54730 & -0.00000 & -0.00000 & 0.00000 & 0.00000 \\
\hline
\end{tabular}

Table 1 shows that for $n=-0 \cdot 15$, the temperature in a part of the boundary layer is less than that outside the boundary layer. Table 2 shows that for $n=-0.3$ the effect is more pronounced and is sufficient to cause flow reversal in the outer part of the boundary layer as indicated by the negative values of $f^{\prime}$.

The physical picture of the phenomena is that the rate of heat transfer from the plate to the fluid in the outer part of the boundary layer is not sufficient to keep its temperature in step with the temperature outside the boundary layer, as it moves upwards.

The possibility that the above described temperature minimum, and flow reversal, may constitute an unstable condition is suggested 
Table 2. Theoretical solution $n=-0 \cdot 3, \mathrm{Pr}=0.708$

\begin{tabular}{|c|c|c|c|c|c|}
\hline$\eta$ & $f$ & $f^{\prime}$ & $f^{\prime \prime}$ & $\Phi$ & $\Phi^{\prime}$ \\
\hline 0.00 & $0 \cdot 00000$ & 0.00000 & 0.64099 & 1.00000 & $-0 \cdot 60414$ \\
\hline 0.50 & 0.06090 & 0.20845 & 0.21979 & 0.70089 & -0.58180 \\
\hline 1.00 & $0 \cdot 18034$ & $0 \cdot 24846$ & -0.03083 & 0.43271 & -0.47702 \\
\hline 1.50 & 0.29536 & 0.20374 & -0.12652 & $0 \cdot 23255$ & -0.32119 \\
\hline 2.00 & $0 \cdot 38072$ & 0.13771 & -0.12746 & $0 \cdot 10863$ & $-0 \cdot 18113$ \\
\hline $2 \cdot 50$ & 0.43491 & 0.08191 & -0.09355 & 0.04342 & -0.08782 \\
\hline 3.00 & 0.46572 & 0.04426 & -0.05822 & 0.01371 & -0.03684 \\
\hline 3.50 & 0.48176 & 0.02204 & -0.03249 & 0.00211 & -0.01282 \\
\hline 4.00 & 0.48946 & 0.01011 & -0.01664 & -0.00145 & -0.00298 \\
\hline 4.50 & 0.49286 & 0.00422 & -0.00787 & -0.00193 & $0 \cdot 00037$ \\
\hline 5.00 & 0.49421 & 0.00153 & -0.00341 & -0.00150 & $0 \cdot 00111$ \\
\hline 5.50 & 0.49465 & 0.00041 & -0.00131 & -0.00096 & 0.00098 \\
\hline 6.00 & 0.49474 & 0.00002 & -0.00041 & -0.00055 & 0.00066 \\
\hline 6.50 & 0.49471 & -0.00009 & -0.00007 & -0.00029 & 0.00039 \\
\hline 7.00 & 0.49467 & -0.00009 & 0.00004 & -0.00014 & 0.00021 \\
\hline $7 \cdot 50$ & 0.49463 & -0.00006 & 0.00005 & -0.00006 & 0.00011 \\
\hline 8.00 & 0.49460 & -0.00004 & 0.00004 & -0.00003 & 0.00005 \\
\hline $8 \cdot 50$ & 0.49459 & -0.00002 & 0.00003 & -0.00001 & 0.00002 \\
\hline 9.00 & 0.49458 & -0.00001 & 0.00002 & 0.00000 & 0.00001 \\
\hline $9 \cdot 50$ & 0.49457 & -0.00000 & $0 \cdot 00001$ & 0.00000 & 0.00000 \\
\hline 10.00 & 0.49457 & -0.00000 & 0.00000 & 0.00000 & 0.00000 \\
\hline $10 \cdot 50$ & 0.49457 & -0.00000 & 0.00000 & 0.00000 & -0.00000 \\
\hline 11.00 & 0.49457 & -0.00000 & 0.00000 & 0.00000 & 0.00000 \\
\hline 11.50 & 0.49457 & 0.00000 & $0 \cdot 00000$ & 0.00000 & $0 \cdot 00000$ \\
\hline 12.00 & 0.49457 & 0.00000 & $-0 \cdot 00000$ & 0.00000 & 0.00000 \\
\hline $12 \cdot 50$ & 0.49457 & 0.00000 & -0.00000 & 0.00000 & 0.00000 \\
\hline 13.00 & 0.49457 & 0.00000 & -0.00000 & 0.00000 & 0.00000 \\
\hline 13.50 & 0.49457 & -0.00000 & -0.00000 & 0.00000 & $0 \cdot 00000$ \\
\hline 14.00 & 0.49457 & -0.00000 & -0.00000 & 0.00000 & 0.00000 \\
\hline $14 \cdot 50$ & 0.49457 & -0.00000 & -0.00000 & 0.00000 & -0.00000 \\
\hline 15.00 & 0.49457 & -0.00000 & -0.00000 & 0.00000 & $-0 \cdot 00000$ \\
\hline $15 \cdot 50$ & 0.49457 & -0.00000 & -0.00000 & 0.00000 & -0.00000 \\
\hline 16.00 & 0.49457 & -0.00000 & -0.00000 & 0.00000 & -0.00000 \\
\hline 16.50 & 0.49457 & -0.00000 & -0.00000 & 0.00000 & $-0 \cdot 00000$ \\
\hline 17.00 & 0.49457 & -0.00000 & 0.00000 & 0.00000 & -0.00000 \\
\hline $17 \cdot 50$ & 0.49457 & -0.00000 & 0.00000 & 0.00000 & $-0 \cdot 00000$ \\
\hline 18.00 & 0.49457 & -0.00000 & 0.00000 & 0.00000 & -0.00000 \\
\hline $18 \cdot 50$ & 0.49457 & -0.00000 & 0.00000 & 0.00000 & -0.00000 \\
\hline $19 \cdot 00$ & 0.49457 & 0.00000 & 0.00000 & 0.00000 & -0.00000 \\
\hline $19 \cdot 50$ & 0.49457 & 0.00000 & 0.00000 & 0.00000 & -0.00000 \\
\hline $20 \cdot 00$ & 0.49457 & $0 \cdot 00000$ & 0.00000 & $0 \cdot 00000$ & 0.00000 \\
\hline
\end{tabular}

by experiments in which negative $n$ existed (or was suspected). The evidence is all indirect and no experiments have yet been carried out to check this idea directly. In all cases the variation of $n$ was imposed by conditions not controlled during the experiment so that the condition $\theta_{w}-\theta_{\infty}=A X^{n}$ was not satisfied. Nonetheless, it is felt that an estimation of the effects can be obtained by the representation of $\theta_{w}-\theta_{\infty}(X)$ as $A X^{n}$ in a piecewise manner.

In experiments reported by Cheesewright $[2,16], n$ was always negative and may have been as low as -0.1 in some cases. The "laminar" boundary layer in these experiments almost always unsteady. It is believed that the only two days during a period of several months on which 
the boundary layer was steady were characterized by $n \bumpeq 0$, but definite evidence on this point does not exist. The introduction of artificial disturbances into the laboratory, outside the boundary layer, did not appear to affect the steadiness in either the steady or the unsteady situation. Further details on these points are given in [2].

These results are in keeping with those reported by a number of authors who have studied boundary-layer flow regimes in closed cavity natural convection, (Elder [11], Carlson [12], Gaster and Murgatroyd [13], Watson [14] and Hammitt [15]). In all cases it has been reported that it is very difficult, or impossible, to obtain steady laminar flow. In all cases substantial variations of $\theta_{\infty}$ (considering the boundary layers on the cell walls) with respect to $X$ occurred, and while it is realized that the closed cavity imposes more severe conditions with regard to stability than a free flow, it is felt that the phenomena are generally the same.

The possibility that unstable flows may occur for $\boldsymbol{n}$ less than some particular value, could explain the unusual results of Tritton [17] who reported a change in the stability of the laminar boundary layer due to a change in laboratory conditions which he was not able to specify. His laboratory was generally similar to that used by Cheesewright [2] so that similar values of $n$ may have occurred.

Cheesewright [16] has also reported increased local heat-transfer rates under conditions for which $n$ was known to be negative. The increase was always greater than that predicted by the laminar steady-state solution. The difference is believed to be due to the unsteadiness discussed above.

\section{CONCLUSIONS}

1. Similarity solutions exist for problems of laminar natural convection from a plane vertical surface in non-isothermal surroundings. The conditions for these solutions may be obtained by the generalization of conditions for solutions in isothermal surroundings.
2. For the special case of an isothermal surface in non-isothermal surroundings $\left(\theta_{w}-\theta_{\infty}=\right.$ $A X^{n}$ ) with $n<0$, a temperature minimum and a region of reversed flow occur within the boundary layer. Experimental evidence suggests that this is an unstable situation.

3. For the above special case, the effect of negative $n$ is to increase the local heat-transfer rate while positive $n$ decreases it.

\section{ACKNOWLEDGEMENTS}

The author is happy to acknowledge the helpful advice of Professor E. J. LeFevre during this work and also of Professor F. G. Hammitt during the preparation of the paper.

The work contained in this paper formed part of the author's Ph.D. Thesis at Queen Mary College, University of London. The use of the facilities of Queen Mary College during this work is gratefully acknowledged.

\section{REFERENCES}

1. K. T. YANG, Possible similarity solutions for laminar free convection on vertical plates and cylinders, J. Appl. Mech. 82, 230-236 (1960).

2. R. CheEsewright, Natural convection from a vertical plane surface, Ph.D. Thesis, University of London, (September 1966).

3. R. G. SchwiNd and G. C. Vliet, Observations and interpretations of natural convection and stratification in vessels, in Proceedings of the 1964 Heat Transfer and Fluid Mechanics Institute, pp. 51-68. Stanford University Press, Stanford, California (1964).

4. S. OSTRACH, An analysis of laminar natural-convection flow and heat transfer about a flat plate parallel to the direction of the generating body force, NAACA, TN 2635 (1952).

5. A. G. HANSEN, Similarity Analysis of Boundary Value, Problems in Engineering. Prentice Hall, London (1964).

6. Pau-Chang Lu, On similarity solutions for flow past flat plates, E, 28(3), 454 (1961).

7. E. M. Sparrow and J. L. GreGG, Similar solutions for free convection from a non-isothermal vertical plate, Trans. Am. Soc. Mech. Engrs 80, 379 (1958).

8. R. EICHHORN, The effect of mass transter on free convection, J. Heat Transfer 82, 260 (1960).

9. E. M. Sparrow, J. L. GreGg and R. EichHorn, Combined forced and free convection in boundary layer flows, Physics Fluids 2, 319-328 (1959).

10. J. BRINDLEY, An approximation technique for natural convection in a boundary layer, Int. J. Heat Mass Transfer 6 (12), 1035-1049 (1963).

11. J. W. ELDER, Laminar free convection in a vertical slot, J. Fluid Mech. 23, 77 (1965).

12. W. D. Carlson, A study of natural convection in a closed cavity using an interferometer, Ph.D. Thesis, University of Minnesota (1956). 
13. M. Gaster and W. Murgatroyd, Final report on contract 13/5/165/947, Nuclear Eng. Lab., Queen Mary College, London (1961).

14. A. Watson, Natural convection in a closed cylindrical vessel containing a heat generating fluid, Ph.D. Thesis Nuclear Eng. Dept., Queen Mary College, London University (1966).

15. F. G. Hammitr, Natural convection heat transfer in closed vessels with internal heat sources-analytical and experimental study, A.S.M.E. Prep. 58-A-212 (1958).

16. R. Cheesewright, Turbulent natural convection from a vertical plane surface, $J$. Heat Transfer, To be published.

17. D. J. Tritton, Transition to turbulence in free convection boundary layers on an inclined heated plate, J. Fluid Mech. 16 (2), 417 (1963).

\section{APPENDIX}

The Numerical Solution and Asymptotic Properties of the Differential Equations (29) and (30)

The substitution of $F(\eta)=f-f_{\infty}$ and $G(\eta)=$ $\Phi$ into equations (29) and (30), gives for large $\eta$

$$
\begin{gathered}
F^{\prime \prime \prime}+f_{\infty}(n+3) F^{\prime \prime}+G=0 \\
G^{\prime \prime}+\operatorname{Pr}(n+3) f_{\infty} G^{\prime}+4 n \operatorname{Pr} F^{\prime}=0
\end{gathered}
$$

since $F, G, G^{\prime} \rightarrow 0$ as $\eta \rightarrow \infty$.

Equation (42) may be written as

$$
(D+\gamma \operatorname{Pr}) G=-4 n \operatorname{Pr} F
$$

where $\gamma=f_{\infty}(n+3)$.

We may thus eliminate $G$ from equation (41) and obtain

$$
\left[D^{2}(D+\gamma)(D+\gamma P r)-4 n \operatorname{Pr}\right] F=0 .
$$

This equation has a solution of the form

$$
F=\sum_{i}^{4} A i \mathrm{e}^{\alpha_{i} \eta}
$$

where $\alpha_{i}$ satisfies

$$
\alpha^{2}(\alpha+\gamma)(\alpha+\gamma \operatorname{Pr})=4 n \operatorname{Pr} .
$$

For the case $\operatorname{Pr}=1$ it is easily seen that if $-3<n<0$ the roots $\alpha_{i}$ of equation (44) are complex. Under these conditions the solution to equation (43) will be of a damped oscillatory character. The introduction of $P r=0.7$ instead of 1 would not significantly alter this result.

This consideration of the asymptotic behavior of equations (29) and (30) indicates that the oscillatory nature of the solutions of these equations as shown in Tables 1 and 2 is real and is not due to numerical error in the solutions.

The above conclusions were confirmed by the following features noted during the calculation of the solutions.

(i) No oscillations were apparent in solutions for $n=0$, even when solutions were calculated to eight figures, and these results showed complete agreement with those of Ostrach [4].

(ii) The solutions were calculated both by Runge-Kutta integration and by iterated integration (Weyl's method) and complete agreement was found.

(iii) Changes in the accuracy specification which controlled the step size in the selfselecting, variable step size, Runge-Kutta procedure had no effect on the nature of the results, neither had a change in the range of integration.

Further details of the computational methods and comparisons of the relative merits of the two methods are given in Cheesewright [2].

\footnotetext{
Résumé-Cet article présente une étude théorique de la convection naturelle laminaire à partir d"une surface plane verticale dans une ambiance non-isotherme. On a obtenu des conditions d'existence de solutions en similitude. On propose une méthode pour généraliser les conditions appartenant aux solutions en similitude existantes afin d'y inclure l'effet d'une ambiance non-isotherme. Des solutions numériques des équations différentielles résultant de la transformation de similitude sont données dans le cas spécial d'une surface isotherme. Ces résultats suggèrent que certaines variations de la température ambiante peut conduire à un changement de sens de l'écoulement dans la couche limite. Les indications de l'expérience suggèrent que ceci peut être une condition d'instabilité.
}

Zusammenfassung-Es wird eine theoretische Untersuchung der laminaren natürlichen Konvektion an einer ebenen senkrechten Oberfläche in nichtisothermer Umgebung beschrieben. Die Redingungen für 
die Existenz von Ähnlichkeitslösungen werden abgeleitet. Eine Methode wird vorgeschlagen, die Bedingungen, welche die existierenden Ähnlichkeitslösungen enthalten, so zu verallgemeinern, dass sie den Einfluss nichtisothermer Umgebung einschliessen. Numerische Lösungen der gewöhnlichen Differentialgleichungen, die sich als Ähnlichkeitstransformation ergeben werden für den Spezialfall einer isothermen Oberfläche angegeben. Diese Ergebnisse zeigen, dass Änderungen in der Umgebungstemperatur zur Strömungsumkehr in der Grenzschicht führen können. Versuchsergebnisse deuten darauf hin, dass dies eine instabile Bedingung darstellt.

Аннотация-Проведено теоретическое исследование ламинарной естественной конвекции от плоской вертикальной поверхности в неизотермическую окружающую среду.

Найдены условия существования автомодельных решений. ІІредложен метод обобщенил услопий существовапия автомоделыных решепий длп учета влияния неизотермических условий. Численные решения обыкновенных дифференциальных уравнений, полученные в результате автомодельных преобразований, описаны для частного случая изотермической поверхности. Установлено, что для некоторых законов изменения окружающей температуры возможны возвратные движения жидкости в пограничном слое. Экспериментальные данные показывают, что әто может быть следствием гидродинамической неустойчивости . 